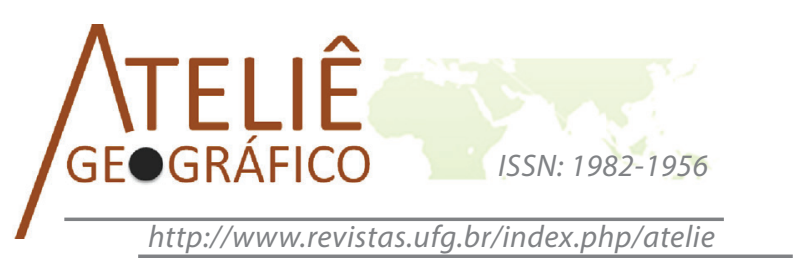

\title{
Paisajes y visualidad: geografias para mirar
}

\author{
Paisagens e visualidade: geografias para olhar \\ Landscapes and visuality: geographies to look at \\ Raquel Gurevich \\ Universidad de Buenos Aires - UBA \\ rgurevich@filo.uba.ar
}

\begin{abstract}
Resumen
La noción de paisaje se asocia a la mirada. En cada escena visual, un fragmento de espacio se hace paisaje. Así los diversos territorios y lugares del mundo aparecen condensados en formatos visuales cada vez más diversificados a través de los medios de información y comunicación de la cultura contemporánea. En este trabajo queremos subrayar que los paisajes devienen de una construcción metodológica particular y no constituyen visiones neutras de cúmulos de elementos. Como los paisajes ilustran la relación entre espacio y vida social, nos importa especialmente tener en cuenta la articulación de referencias locales y globales; los actores sociales intervinientes y las tecnologías dominantes. A lo largo del texto se presentan indicadores para el análisis de los paisajes y recursos para la lectura de las composiciones paisajísticas. Se favorece la construcción e interpretación de múltiples datos, relatos, experiencias y/o testimonios que entrelazan el espacio íntimo y el espacio público, a fin de avanzar en una propuesta conceptual sobre la multiterritorialidad.
\end{abstract}

Palabras claves: paisaje, visualidad, contexto socio-cultural, análisis metodológico.

\section{Resumo}

A noção de paisagem está associada com o olhar. Assim, os vários territórios e lugares do mundo aparecem condensados em formatos visuais cada vez mais diversificados através dos meios de comunicação e cultura contemporânea. Neste trabalho enfatizamos que as paisagens se tornam uma construção metodológica particular e não são visões neutras de aglomerados de elementos. Como as paisagens ilustram a relação entre espaço e vida social, especialmente temos o cuidado de considerar a articulação de referências locais e globais; as partes interessadas e tecnologias dominantes. Ao longo do texto, são apresentados indicadores para a análise de paisagens e recursos para a leitura das composições paisagísticas. Serão 
priorizados a construção e interpretação de múltiplos dados, relatos, experiências e/ ou depoimentos que entrelaçam o espaço íntimo e espaço público, a fim de avançar em uma proposta conceitual sobre multiterritorialidade.

Palavras-chave: paisagem, visualidade, contexto sócio-cultural, análise metodológica.

\begin{abstract}
The notion of landscape is associated with the look. In each visual scene, a fragment of space is made landscape. Thus the diverse territories and places of the world appear condensed in visual formats increasingly diversified through the means of information and communication of the contemporary culture. In this paper we want to emphasize that landscapes come from a particular methodological construction and are not neutral visions of lots of elements. As landscapes illustrate the relationship between space and social life, we especially care to take into account the articulation of local and global references; the intervening social actors and the dominant technologies. The text presents indicators for the analysis of landscapes and resources for reading landscape compositions. It enables the construction and interpretation of varied data, stories, experiences and testimonies that join the intimate space and the public space, in order to advance a conceptual proposal on multiterritoriality.
\end{abstract}

Keywords: landscape, visuality, socio-cultural context, methodological analysis.

"La imagen es una mariposa. Una imagen es algo que vive..." Georges Didi-Huberman

\title{
Introducción
}

Este texto es una invitación a trabajar la noción de paisaje, entendida desde la observación directa hasta el complejo conjunto de operaciones simbólicas incluidas en el acto de mirar. Tal propuesta nos coloca en posición de lectores, frente a la diversidad de los innumerables elementos y acciones que se nos presentan en cada escena paisajística.

Atravesaremos la frontera entre el concepto de paisaje hacia el del territorio, pues comprendemos a los paisajes como la última capa fisonómica de los territorios, en tanto constituyen su apariencia visual, ofreciéndose a nuestro sentido de la vista. Por ello, al estudiar las relaciones entre los elementos y las acciones en los paisajes, avanzamos sobre la dinámica de los respectivos territorios implicados, y cobran relevancia los actores sociales que les otorgan vida, sus prácticas socio-económicas, sus contextos culturales, sus intereses, sus políticas.

En este trabajo deseamos resaltar que los paisajes constituyen un constructo resultado de una construcción metodológica particular, que incluye una trama de habilidades y destrezas de lectura e interpretación visual. Por ello es necesario decodificarlos, analizarlos, compararlos entre sí y complementar la información visual con bancos de documentación, fuentes y materiales diversos. De allí que en los apartados que siguen, apelaremos a la utilización crítica de una trama compleja de conceptos e 
imágenes de todo tipo, que por su carácter histórico y conjetural, nos abren la mirada a un mundo cambiante y no se confunden con fotografías transparentes de la realidad.

\section{Paisajes y miradas: una construcción metodológica}

La noción de paisaje se asocia a la mirada, visiones, perspectivas, encuadres y enfoques. Quién mira, desde dónde, a través de qué dispositivos, a qué distancia, en qué momento, con qué frecuencia: son todos interrogantes que nos acercan a una construcción metodológica particular. Los ámbitos conceptuales y semánticos vinculados con la mirada y el espacio circunscriben un campo de nociones que ponen en foco los diversos territorios y lugares del mundo. En cada escena visual, se recorta un fragmento de espacio, se empiriza, se hace paisaje. Quisiéramos iluminar este punto, para resaltar la idea del carácter parcial, situado y provisional que posee el proceso de construcción de la mirada y del conocimiento, en este caso de los paisajes que en cada caso observamos.

Nogué nos recuerda que “el paisaje no sólo nos muestra cómo es el mundo, sino que es también una construcción, una composición de este mundo, una forma de verlo. Entendiendo, pues, el paisaje como una mirada, como una "manera de ver", es fácil asumir que dichas miradas acostumbran a no ser gratuitas, sino que son construidas y responden a una ideología que busca transmitir una determinada forma de apropiación del espacio. Las miradas sobre el paisaje -y el mismo paisaje- reflejan una determinada forma de organizar y experimentar el orden visual de los objetos geográficos en el territorio" (NOGUE, 2015. P.1).

Sabemos que la mirada enfoca, selecciona y clasifica: no opera como espejo transparente ni representación objetiva ni mucho menos como instrumento neutro de producción de saber. "No hay grado cero de la mirada", por el contrario, la mirada está imbuida y produce, a su vez, símbolos, imaginarios, creencias y valores al mismo tiempo que delimita elementos y procesos específicos. Además, los significados del paisaje también dependen de las tecnologías de producción y percepción de las imágenes (satélites, cámaras, lentes, películas). Apelando al uso de filtros, zooms y pantallas de diferente resolución, tales dispositivos de selección se constituyen en dispositivos para mirar, cargados cada uno de ellos por sus propias definiciones de perspectiva y puntos de vista (Cuadro 1). Así, «la visión» es a la vez una función fisiológica y una capacidad imaginativa en la que de algún modo se presencian fenómenos no-materiales. Las conexiones entre la visión y la imaginación sugieren nuevas complejidades culturales añadidas al sentido de la vista y al acto de ver" (COSGROVE, 2002, P. 71).

Cuadro 1. Trayectos entre la visión y la mirada

ojo-visión-mirada

- perspectiva

- $\quad$ puntos de vista

- enfoques, recortes, zoom

- dispositivos para mirar 
Existe consenso al afirmar, de modo general, que los paisajes constituyen el aspecto fisonómico de los territorios (Santos, 1996), su captura visual, su apariencia visible, compuestos por los objetos y acciones que se nos ofrecen accesibles a través del sentido de la vista. Por ello, la mirada y la perspectiva son componentes claves para las acciones de ver y mirar paisajes. Sin negar otros sentidos humanos, podemos decir que la geografía se encuentra privilegiadamente cerca de estos estímulos. Planteábamos en un texto anterior (Autor, 2013) que el verbo ver, ligado a saber y a conocer, se emparenta con la idea de viaje, de desplazamiento, porque convoca a la asociación con otras ideas, otros paisajes, otras culturas. Ver, mirar, leer, viajar: son todas actividades que involucran de modo decisivo el sentido de la visión, provocando una extensión de la mirada y una ampliación de la experiencia.

Participamos, entonces, de la distinción entre la mirada y la visión, de la profundidad de la lectura respecto del ojo desnudo, del valor de la interpretación por sobre los datos per se. Avanzamos siempre hacia la interpretación, cuando tenemos en cuenta que “...la vista, la visión y el propio acto de ver - como implican estas palabras tan variadas - traen consigo mucho más que una simple respuesta de los sentidos, es decir algo más que la huella pasiva y neutra de las imágenes formadas por la luz en la retina del ojo. La vista humana es individualmente deliberada y está culturalmente condicionada" (COSGROVE, 2002, P. 66).

A partir de la mirada sobre diferentes paisajes, podemos hacer el ejercicio de pensar la categoría espacio y la relación espacio-sociedad. No concibiendo el espacio como un receptáculo o continente, ni como soporte inerte de elementos y relaciones, sino formando parte de la sociedad misma (Blanco, 2007), como aspecto indisoluble en el funcionamiento de la cultura, la política, la economía, las creencias y los sistemas de valores. Y a su vez, en perpetua construcción, en continua transformación. Por ende, los paisajes "están siendo" históricamente, se hallan en permanente recreación, más que representando una forma terminada o una postal concluida.

Los paisajes se nos ofrecen para observar y dotar de sentido a las relaciones dinámicas entre espacio y sociedad, envolventes, comunicantes, que producen y a la vez son mutuamente producidas, en un proceso de acciones recíprocas y efectos intercondicionados entre sí. A partir de mirar las escenas paisajísticas con profundidad histórica, es posible identificar los principales procesos sociales que se hallan allí territorializados: esto implica considerar cómo se han ido fijando y acumulando las diferentes decisiones sociales a lo largo del tiempo. También es posible reconstruir y registrar el proceso incesante de transformación del espacio construido, reparando en cómo las relaciones sociales son producidas y reproducidas en cada uno de los lugares en estudio.

Los paisajes ilustran la relación entre espacio y vida social, en tanto nos dejan a las puertas de la noción de territorio. Sabemos que este último concepto lleva implícita la idea de apropiación, dominio y control de una porción de la superficie terrestre, pero también contiene las ideas de pertenencia y de proyectos que una sociedad desarrolla en un espacio dado. Si bien el ejercicio del poder, la política y las acciones de los Estados resultan centrales en la noción de territorio, éste no se reduce a una entidad jurídico- 
administrativa y su sentido excede el de la dimensión política. En el territorio pensado como proyecto compartido, como ámbito de intersección de experiencias colectivas, se conjugan un sinnúmero de dimensiones sociales, políticas, económicas, simbólicas, que es posible rastrear en el análisis de los paisajes de diferentes lugares y regiones del globo.

Las imágenes de paisajes sorprenden por su permanencia en el tiempo y su capacidad de moldear las instituciones sociales. (...). Se puede observar que las precepciones de un territorio y su historia pueden ser objeto de inculcación, negociación o contestación. (...) en cuanto expresión simbólica del espacio constituye muchas veces, la piedra angular de imaginarios sociales comprometidos con procesos de construcción de un territorio, una región o una nación, y por lo tanto son procesos constitutivos de la identidad de sus habitantes. En general, las identidades sociales (étnicas, religiosas, nacionales) deben mucho de su encanto a la mística de una tradición paisajística particular, a una topografía mapeada, elaborada y enriquecida como tierra natal (..) en algunos imaginarios sociales, el paisaje puede ocupar un lugar aún más importante, haciendo del entorno exterior y visible, la llave misma para la comprensión del sentido de la vida humana. (ORTIZ-OSES y LANCEROS, 2006, p. 439-440)

\section{Operaciones de lectura en las composiciones paisajísticas}

Cada vez que nos preguntamos acerca del dinamismo de las composiciones paisajísticas, avanzamos sobre el movimiento, el funcionamiento y las prácticas que ocurren en los territorios implicados, a través de los actores sociales que les insuflan vida, deseos, racionalidades, intereses, políticas.

En el estudio de los paisajes, al profundizar en las transformaciones y en la vida que los anima, se tiene oportunidad de vincular de otro modo el conocimiento y la investigación con las prácticas de creación y reflexión, promoviendo nuevos modelos de invención y narración en el campo de la geografía. En esta tarea, colaboran las producciones teóricas que capturan la cotidianeidad en los diferentes lugares, cuando pintan retratos empíricos que recuperan lo mejor de la tradición descriptiva, renovándola y dinamizándola desde un entramado de conceptos e imágenes, que hacen nacer nuevas categorías de reflexión. Resulta fructífero preguntarnos qué paradigmas de la geografía podrían ser los mejores interlocutores con estas formas de representación de los territorios: si uno relacional, uno crítico, uno humanista, uno testimonial o cuál otro.

Cada lugar, presentado fisonómicamente como paisaje, puede entenderse como una articulación de múltiples pertenencias. El cruce de referencias locales y globales, propias y ajenas, de adentro y de afuera, cercanas y lejanas, vislumbra el inicio de un camino muy interesante que dota de nuevos sentidos la posible inscripción a una perspectiva diferente de la geografía humana o vivencial, aglutinadora de elementos locales y no locales. Resulta iluminadora la noción de espacio de Doreen Massey (2005) como "producto de interrelaciones, desde lo inmenso de lo global hasta lo ínfimo de la intimidad". En este sentido, concebir los respectivos lugares del mundo como cruces entre macroestructuras sociales más generales y otras de orden más biográfico, 
natales, íntimos, domésticos. Es oportuno reflexionar acerca de qué aspectos de la vida social y del territorio, representados en los paisajes, es posible conocer, profundizar, narrar o investigar desde geografías que cruzan múltiples escalas de análisis -macro y microescalares-, que incorporan detalles pequeños, sin desconocer las tendencias de la organización social y productiva de conjunto. Detenerse en aquellos aspectos locales, cotidianos, biográficos, que brindan información del contexto histórico, permite una mayor apertura temática y de significación. Al mismo tiempo, se trata de datos que le dan vida al territorio, al rescatar su dimensión cotidiana y simbólica.

Tú me hablas de capacidad de verdad, y yo lo que digo es que esa capacidad de verdad hay que temporalizarla, hay que entender que sólo ocurre en momentos muy breves. (...) Y eso es lo que me interesa. Hace poco he acabado un texto sobre la imagen como mariposa. Si realmente quieres verle las alas a una mariposa primero tienes que matarla y luego ponerla en una vitrina. Una vez muerta, y sólo entonces, puedes contemplarla tranquilamente. Pero si quieres conservar la vida, que al fin y al cabo es lo más interesante, sólo veras las alas fugazmente, muy poco tiempo, un abrir y cerrar de ojos. Eso es la imagen. La imagen es una mariposa. Una imagen es algo que vive y que sólo nos muestra su capacidad de verdad en un destello. (DIDI HUBERMAN, 2007, p. 19)

Desde el punto de la vista metodológico, trabajando los paisajes como “composición”, es posible visualizar la articulación entre las coordenadas espaciotemporales que se expresan en cada lugar del globo, atendiendo a los siguientes analizadores (Cuadro 2):

Cuadro 2. Analizadores de las composiciones paisajísticas

\begin{tabular}{ll|}
\hline - & singularidad del lugar \\
- & dimensión temporal y estacional \\
- & cambios, transformaciones \\
- & condiciones originales \\
- & actores sociales implicados \\
\hline
\end{tabular}

Focalicemos un momento en la zona de articulación entre los rasgos singulares de un paisaje y las condiciones generales de producción de territorios. Así, los procesos de transformación de las sociedades y de la naturaleza, en cada contexto socio-político que estemos analizando, actuarán como marcos generales de interpretación de los rasgos singulares de cada paisaje. Ningún paisaje será decodificado en soledad, entendido aisladamente, sino en permanente relación con los entornos y los contextos, en sintonía con los múltiples procesos socio-culturales y políticos que desarrollan en cada lugar o región del globo.

Sabemos que los paisajes son constructos siempre cambiantes, en configuración permanente y abiertos todo el tiempo a ser recreados y modificados por los diferentes grupos sociales que en ellos y fuera de ellos desarrollan sus actividades y proyectos. Y no 
podría ser de otra manera, porque estamos tratando un contenido que comparte complejas características con la noción de territorio: como producto y productor de relaciones sociales; con la vida social incrustada como herencia y, a la vez, como instrumento de cambio; como reproducción y, a la vez, como posibilidad de diferencia.

Entonces, por un lado, la multiplicidad y la diversidad de la vida social se singularizan según los lugares en los que acontecen las historias y se plasman en paisajes. En ellos observamos líneas de articulación y líneas de ruptura, como rasgos salientes de nuestro tiempo, ya sea entre los grupos sociales, las culturas, las instituciones, las comunidades. La simultaneidad temporal coexiste con la diferenciación geográfica en cada lugar, permitiendo reconocer procesos de territorialización de índole funcional (político y económico) y simbólico (de identificación cultural).

Otro componente que añade densidad al análisis son las relaciones entre horizontalidades (lazos de contigüidad espacial, entre vecinos, que aluden a la continuidad territorial) y verticalidades (que aluden a puntos distantes unos de otros, ligados por vectores productivos, sociales y tecnológicos). La coexistencia de las horizontalidades a escala local y las verticalidades en escalas nacionales o globales alude a un tiempo social que no es único, que presenta diferentes ritmos y velocidades en los distintos lugares. Converge el tiempo, con múltiples posibilidades empíricas de experiencias.

En efecto, en cada lugar se observan funcionalidades diferentes, de acuerdo a los tipos de aconteceres simultáneos que se desarrollen (Santos, 1996). Se presentan bajo tres formas: homólogo, complementario y jerárquico. El primero alude a las actividades o funciones rurales o urbanas que pueden observarse en áreas bien delimitadas, uniformes que gozan de contigüidades funcionales. Por su parte, el acontecer complementario supone relaciones e intercambios entre diferentes territorios no necesariamente contiguos: entre campo y ciudad; entre el turismo y el patrimonio natural y cultural que oferta un lugar; entre oferta y demanda de trabajo entre dos países. Finalmente, el acontecer jerárquico comprende relaciones de orden, comando, control y decisión. Este último acontecer se relaciona con las prácticas sociales materializadas en el marco del sistema de normas y regulaciones que organizan el funcionamiento de un territorio. Dichas prácticas se visualizan en el nivel político, legal, diplomático, mediático, tecnológico, financiero, en los servicios diferenciales y especializados. Este conjunto de regulaciones incluye desde la armazón jurídica hasta los procedimientos que fija una gran empresa transnacional para la organización del trabajo o los que practica la prensa local o internacional.

Resulta pertinente volver al análisis de la relación singular-general. Cada paisaje constituye una totalidad, una visión de conjunto del mundo y, al mismo tiempo, articula partes y diferencias. Ofrece referentes empíricos propios de cada lugar. Las funcionalizaciones concretas nos acercan a sujetos, relaciones y objetos particulares. No hay ningún lugar igual a otro, por cierto "cada lugar devela el mundo" y "en cada lugar se realiza el mundo" (Santos, 1996; Benko, 1994). Pero esas condiciones específicas, particulares de cada lugar no podrán desplegarse sino en condiciones y contextos históricamente situados, con determinadas condiciones políticas, sociales, culturales, económicas. 


\section{Los lugares y los datos visuales: tramas cambiantes}

Los lugares aglutinan redes de relaciones sociales que ligan comunidades e identidades diversas. La heterogeneidad define la vida social, la dinámica de las sociedades, los territorios y las culturas, alienando toda identidad radical. Ocurre diariamente una permanente configuración-reconfiguración, en tanto se redefinen en el cotidiano las tramas sociales, culturales, económicas, políticas y tecnológicas.

En cada lugar, visionado a través del paisaje, se sintetizan dos componentes básicos: materialidad y símbolos. Contamos entonces una gran cantidad de información visual, en tanto "el status de la imagen como representación es tan importante como las transacciones de información que permite" (MOXEY, 2009, pag.15).

Nos convoca la tarea de decodificar, fusionar, comparar y complementar dicha información visual con bancos de documentación, fuentes y materiales diversos. Vale entonces desarrollar las siguientes actividades (Cuadro 3):

Cuadro 3. Enlaces entre la captación visual y otras fuentes de información

- identificar elementos y sus relaciones;
- $\quad$ reconocer la proximidad y la distancia;
- identificar regularidades;
- reconocer peculiaridades;
- adjudicar razones y causalidades;
- $\quad$ inferir lo invisible.

Si traemos a nuestra memoria algunas imágenes que tenemos sobre ciertos lugares del mundo (recuerdos de infancia, visiones desde la ventanilla de un medio de transporte, fotos de revistas, escena de alguna película y por qué no algún fragmento de una novela que haya conseguido hacer del paisaje un verdadero protagonista de la historia), podemos poner a trabajar las categorías que venimos comentando.

En cuanto a los elementos y a la composición, muy probablemente en todas esas imágenes aparezcan las condiciones naturales (formas de relieve, ríos, vegetación, condiciones climáticas) y/o los elementos construidos fijados a la superficie terrestre (incluidos los mares y océanos del mundo, pues en tiempos contemporáneos dichos constructos se instalan también en entornos marítimos e insulares). Nos referimos a las construcciones y edificios, caminos y rutas, puertos y aeropuertos, emplazamientos diversos que forman parte del patrimonio cultural, infraestructura energética o de circulación, entre otros, pensados como objetos agregados a lo largo del tiempo que van constituyéndose en una cualidad propia de cada uno de los lugares. Esas formas construidas, denominadas por M. Santos "rugosidades", son formas durables o temporarias, aisladas o como conjuntos (Santos, 1996) que desempeñan un papel central en el modelado de la espacialidad de la vida social. Dichos constructos pueden ser analizados desde múltiples opciones temáticas y conceptuales: tanto un enfoque 
tecnológico, como uno arquitectónico, uno histórico o también desde el punto de vista funcional.

Mucho se ha escrito acerca de la asociación automática entre la noción de paisaje y la de paisaje natural. Con lo expuesto hasta aquí, queda clara nuestra posición respecto de la construcción e inversión histórica y social en la configuración de los territorios y en consecuencia, de los paisajes. Si en particular reparamos en la dimensión ambiental de los paisajes, en muchas ocasiones se visualizan en forma explícita las relaciones sociales que transforman y modelan las condiciones naturales de los territorios. En otras, no es tan evidente, pero aun así ellas impactan en las formas paisajísticas. Advertidos de esta intervención, la mirada se politiza, se socializa, adquiere espesor histórico. Con "otro modo de ver" la naturaleza, nos encontraríamos cerca de una contemplación más neutra o una visión naturalizante. En efecto, Andermann (2008) plantea que "el paisaje es el archivo físico donde están trazadas las relaciones sociales de la naturaleza", haciendo hincapié en que no hay "retorno a la naturaleza, por el contrario, lo que habría que recuperar es una noción del paisaje que supiera dar cuenta de su posición intersticial y oscilante entre imagen y entorno, como aquello que ensambla la construcción perceptiva con los efectos que ésta produce en la materialidad de lo que abarca" (ANDERMANN, 2008, P. 6).

Respecto de las regularidades y las causalidades, nos encontramos frente a la multiplicidad de la espacialidad, en su doble dimensión: material e inmaterial, que incluye tanto objetos diversos como los que hemos mencionado antes, como conjuntos de ideas, creencias, representaciones, sistemas de valores y flujos de todo tipo (culturales, mediáticos, tecnológicos, financieros, publicitarios). Así, contextos y entornos procedentes de cualquier lugar del mundo quedan plasmados en escenas cotidianas de los lugares, y nos evocan la noción de espacio no como envoltorio o recipiente de estos aspectos de las sociedades, sino como parte intrínseca de la vida social.

Dicha multiplicidad implica al lector/observador, en el sentido de terminar de "componer" las imágenes, con su trabajo de interpretación, de producción, de imaginación (Appadurai, 2001; Harvey, 2005, Zusman, 2013) y así revisitar a través del análisis de paisajes, la relación mundo-lugar: el mundo como mosaico, en parcelas, no a modo de encastre perfecto, sino de multiplicidad de fragmentos a diferentes escalas de resonancia. Vale aquí la muy acertada expresión de "fraccionamiento articulado" más que "articulación de los fragmentos", con la que García Canclini definía "lo que suele llamarse globalización (...) como un conjunto de procesos de homogeneización $\mathrm{y}$, a la vez, de fraccionamiento articulado del mundo, que reordena las diferencias y las desigualdades sin suprimirlas" (García Canclini, 1999. P. 48-49).

\section{Para finalizar: los paisajes, entre la fluidez y el anclaje territorial}

Desde nuestra perspectiva de análisis, hemos estado adentrándonos en los paisajes: yendo de la superficie y la forma, hacia la profundidad y los procesos (Cuadro 4). En especial, para recuperar las acciones sociales, expresiones culturales, proyectos y conflictos que cotidianamente se hacen presentes en cada lugar del mundo. 
Cuadro 4. Imágenes y Espacio social: de los paisajes a los territorios

- $\quad$ superficie profundidad

Nos interesa subrayar que la fluidez y la inmaterialidad de los flujos contemporáneos no opacan el anclaje territorial, los procesos sociales situados y localizados de modo particular, territorializados al fin, en los diferentes puntos del globo. Es preciso detenernos en el concepto territorio, para analizar más profundamente los paisajes.

Desde un enfoque multiterritorial, que concibe el territorio como apropiación y también como subjetivación, la noción de territorio lleva implícita la idea de apropiación, dominio y control de una porción de la superficie terrestre, pero también contiene las ideas de pertenencia y de proyectos que una sociedad desarrolla en un espacio dado. $\mathrm{Si}$ bien el ejercicio del poder, la política y las acciones de los Estados resultan centrales en la noción de territorio, éste no se reduce a una entidad jurídico-administrativa y su sentido excede el de la dimensión política. Así, es posible vincular los sujetos y la vida social, los sujetos y las instituciones, los sujetos y las estructuras. Se enlazan las vidas singulares, los proyectos individuales con procesos sociales más amplios y se presentan las vidas de los sujetos en contexto, habilitando relatos, experiencias, vivencias, encuentros que entrelazan el espacio íntimo y el espacio público.

La propuesta conceptual de Rogerio Haesbaert (2005) sobre la multiterritorialidad se constituye en un aporte muy interesante para capturar las características de los territorios contemporáneos que venimos presentando. Tener en cuenta las múltiples territorialidades existentes que confluyen en un punto del globo, según las racionalidades y acciones de los actores en juego en cada caso, habilita pensar procesos de territorialización múltiples en el contexto de las nuevas formas de desplazamiento territorial de las sociedades actuales, sin minimizar el peso de los Estados-nación y de los agrupamientos regionales. Esta última posición recupera las múltiples pertenencias que caracterizan los lugares contemporáneos, “contra el mito de la desterritorialización”, como él mismo señala.

Es prometedor y comprometedor abocarnos a la tarea de trabajar con múltiples y complejas representaciones (textuales y visuales, y en movimiento) y por qué no expandir el repertorio a otras múltiples (acústicas y táctiles, por ejemplo) que den cuenta de geografías de la multiplicidad, de las diferencias y la desigualdad, territorios entre la homogeneidad y la fragmentación; entre la fluidez y el anclaje; entre lo público y lo privado; entre la objetividad y la subjetividad. En palabras de Andermann (2008), "paisaje-ensamble, o imagen-movimiento: es hacia esa cinemática natural pos-kantiana, creo, que habría que avanzar a fin de construir la historicidad del paisaje y, así, dotarlo nuevamente de futuridad" (ANDERMANN, 2008, P. 6).

Cuenta Regis Debray (1994) en el inicio de su libro Vida y muerte de las imágenes, que "un emperador chino pidió un día al primer pintor de su corte que borrara la cascada que había pintado al fresco de la pared del palacio porque el ruido del agua le impedía dormir" (DEBRAY, 1994, P.13). Quizás esta famosa anécdota pueda servir de 
estímulo y provocación para expandir, cada vez más, las fuentes de conocimiento y los modos de investigar, preguntar y comunicar experiencias e intervenciones en distintos paisajes del mundo.

\section{Referencias}

APPADURAI, Arjun. La modernidad desbordada. Dimensiones culturales de la globalización. Buenos Aires: Ediciones Trilce-Fondo de Cultura Económica, 2001.

ANDERMANN, Jens. "Paisaje: Imagen, entorno, ensamble". En: Revista Orbis Tertius. Año 13 Nro. 14. La Plata: Universidad Nacional de La Plata, 2008, p. $1-6$.

ARFUCH, Leonor. "Dilemas de ver: modos de ver y de ser". En: Rayando los confines. Sección Reflexiones. Buenos Aires: Facultad de Ciencias Sociales, UBA, 2009. Disponible en www.rayandolosconfines.com

BAL, Mieke. Conceptos viajeros en Humanidades. Una guía de viaje. Murcia: CENDEAC, 2009.

BENKO, Georges. "Geografia do lugar nehum ou hiperglobalização. Breve examen do mundo pos-moderno". En: Santos, M. De Souza, M.A y Silveira, M.L. Território. Globalização e fragmentação. São Paulo: Editora Hucitec. ANPUR, 1994.

BLANCO, Jorge. "Espacio y territorio: elementos teórico-conceptuales implicados en el análisis geográfico". En: Fernández Caso, V. y R. Gurevich (coord) Geografia. Nuevos temas, nuevas preguntas. Un temario para su enseñanza. Buenos Aires: Editorial Biblos, 2007. p.37-64.

BRUNER, Jerome. La fábrica de historias. Derecho, literatura, vida. Buenos Aires: Fondo de Cultura Económica, 2003.

COSGROVE, Denis. "Observando la naturaleza: el paisaje y el sentido europeo de la vista". En Boletín de la A.G.E. Nro. 34. Madrid: Asociación de Geógrafos Españoles, 2002. p. 63-89.

DEBRAY, Regis. Vida y muerte de la imagen. Historia de la mirada en Occidente. Barcelona: Paidós, 1994.

DIDI-HUBERMAN, George. "Un conocimiento por el montaje". Entrevista con George Didi Huberman, por Pedro Romero, en Revista Minerva Nro. 5. Madrid. Revista del Círculo de Bellas Artes, IV Época Cuando la imagen toca lo real. 2007, p.17-22

FERNANDEZ POLANCO, Aurora. Pensar la imagen. Pensar con las imágenes. Madrid: Editorial Delirio, 2014.

GARCIA CANCLINI, Néstor. La globalización imaginada. México: Paidós, 1999.

GARCIA CANCLINI, Néstor. El mundo entero como lugar extraño. Serie Cultura. Buenos Aires: Editorial Gedisa, 2014. 
GUREVICH, Raquel "Geografías para leer, mirar y viajar. La noción de paisaje en análisis y experiencias". En: Garrido, Marcelo (comp.) La Opacidad del Paisaje Escolar. Formas, imágenes y tiempos educativos. Porto Alegre-Brasil: ComPasso e Imprensa Livre Editores. 2013, P. 25-35.

GUREVICH, Raquel "Babel. Ecos de geografías y territorios". En: Revista Huellas Nro. 13 Primavera 2009. Universidad Nacional de La Pampa: Miño y Dávila Editores / Instituto de Geografía. Facultad de Ciencias Humanas. 2009, P. 37-63.

HAESBAERT, Rogelio "De la desterritorialización a las multiterritorialidades". Ponencia en la Conferencia Internacional Aspectos culturales en las Geografías económicas, sociales y políticas. UGI. Unión Geográfica/ Instituto de Geografía, Buenos Aires, UBA. 2007.

HARVEY, David "The sociological and geographical imaginations", En: International Journal of Politics, Culture, and Society. 2005, Vol. 18 3/4. 2005, P.211-255.

HOLLMAN, Verónica. "La espacialidad de las imágenes y el acto de mirar". En: Biblio 3W. Revista Bibliográfica de Geografía y Ciencias Sociales. Barcelona: Universidad de Barcelona, 5 julio 2015, Vol. XX, n 1125. P.1-6

MARTINEZ DE PISON, Eduardo: "Saber ver el paisaje”, En: Estudios Geográficos Vol. LXXI, Julio-Diciembre 2010. P. 395-414

LOIS, Carla y Verónica HOLLMAN (Eds). Geografía y cultura visual. Los usos de las imágenes en las reflexiones sobre el espacio, Rosario: Prohistoria Ediciones/ Universidad Nacional de Rosario, 2013.

MASSEY, Doreen. "La filosofía y la política de la espacialidad: algunas consideraciones". En: Arfuch, L. (comp.) Pensar este tiempo. Espacios, afectos, pertenencias. Buenos Aires: Paidós. 2005, P. 101-128.

MAYER, Marcos. John Berger y los modos de mirar. Serie Intelectuales. Madrid: Campo de ideas, 2004.

MOXEY, Keith. Los estudios visuales y el giro icónico. Revista EV Estudios Visuales. Nro. 6. Enero 2009. Murcia: CENDEAC. P. 8-29.

NOGUE, Joan. "El retorno al paisaje". En: Enrahonar. Quaderns de filosofia. Nro. 45, Universidad Autónoma de Barcelona, 2010. 123-136

NOGUE, Joan. "La construcción social del paisaje". Documento leído en el 6to Encuentro Nacional de la Red Argentina del Paisaje. Universidad de Palermo: Buenos Aires. Disponible en http://www.redargentinadelpaisaje.com., 2015

ORTIZ-OSES, Andrés y Patxi Lanceros (Dir). Diccionario de la Existencia. Asuntos relevantes de la vida humana. Barcelona: Antrophos Editorial. En colaboración con la UNAM. Centro Regional de Investigaciones Multidisciplinarias, 2006. 
SANTOS, Milton. A natureza do espaço. Técnica e tempo. Razão e Emoção. São Paulo: Editora Hucitec, 1996.

ZUSMAN, Perla. "La geografía histórica, la imaginación y los imaginarios geográficos". En: Revista de Geografia Norte Grande Nro.54. Santiago de Chile, Mayo 2013. Disponible en: www.scielo.cl

Raquel Edith Gurevich

Profesora de Geografía, Departamento e Instituto de Geografía, Facultad de Filosofía y Letras de la Universidad de Buenos Aires UBA. Se desempeña en las Cátedras de Geografía Social Argentina y Didáctica Especial de la Geografía. Calle Puan 430 Ciudad de Buenos Aires, CABA, Argentina.

E-mail: rgurevich@filo.uba.ar

Recebido para publicação em janeiro de 2017 Aprovado para publicação em abril de 2017 